Article

\title{
Probabilistic Fatigue Life Prediction of Bridge Cables Based on Multiscaling and Mesoscopic Fracture Mechanics
}

\author{
Zhongxiang Liu ${ }^{1}$, Tong Guo ${ }^{1, *}$ and Shun Chai ${ }^{2}$ \\ 1 Key Laboratory of Concrete and Prestressed Concrete Structure, Ministry of Education, Southeast University, \\ 2 Sipailou, Nanjing 210096, China; lzxyueguang@outlook.com \\ 2 School of Civil Engineering, Southeast University, 2 Sipailou, Nanjing 210096, China; chaiziyjs@outlook.com \\ * Correspondence: guotong@seu.edu.cn; Tel./Fax: +86-25-83790923
}

Academic Editor: César M. A. Vasques

Received: 22 October 2015; Accepted: 9 March 2016; Published: 7 April 2016

\begin{abstract}
Fatigue fracture of bridge stay-cables is usually a multiscale process as the crack grows from micro-scale to macro-scale. Such a process, however, is highly uncertain. In order to make a rational prediction of the residual life of bridge cables, a probabilistic fatigue approach is proposed, based on a comprehensive vehicle load model, finite element analysis and multiscaling and mesoscopic fracture mechanics. Uncertainties in both material properties and external loads are considered. The proposed method is demonstrated through the fatigue life prediction of cables of the Runyang Cable-Stayed Bridge in China, and it is found that cables along the bridge spans may have significantly different fatigue lives, and due to the variability, some of them may have shorter lives than those as expected from the design.
\end{abstract}

Keywords: probabilistic analysis; fatigue crack growth; cable; steel wire; cable-stayed bridge; multiscaling; mesoscopic fracture mechanics

\section{Introduction}

Cable supported bridges, particularly the cable-stayed bridges and suspension bridges, have been widely used owing to their appealing aesthetics, strong ability to reduce bend moment of the cross section and high spanning capacity [1]. Among the most important components, cables are usually designed with a relatively high safety factor (i.e., ranging from 2.2 to 4.2). Nevertheless, subjected to fatigue, corrosion or their coupled effects, etc., many cables showed premature damage only a few years after the bridges were open to traffic, resulting in traffic interruption, maintenance costs and even collapse [2-4]. As the stock of aging cable supported bridges is steadily increasing, accurate assessment of fatigue lives of cables is both important and urgent to secure the operation and safety of bridges.

The difficulty in accurate prediction of cable life is partly due to the highly uncertain nature in fatigue analysis, existing in material properties, external loads and prediction models, etc. Previously, numerous experimental studies have been made on the fatigue performance of cables, which showed different kinds and degrees of uncertainty [5,6]. For example, laboratory tests [5] on a group of degraded cables showed that the Young's modulus and the ultimate strain follow the normal distributions, with the mean values of $199.5 \mathrm{GPa}$ and $44.4 \mathrm{~m} \varepsilon$ and the coefficients of variance (COVs) of 0.27 and 0.0181 , respectively, whereas the yield and ultimate stresses follow the Weibull distributions.

The uncertainties in external loads, on the other hand, are often learned from field inspection or monitoring, and vehicle loads usually contribute mostly to the randomness. Some proposed that vehicle load models showed that the vehicles passing across the bridge are not only probabilistic but also site-specific [7-9]. In order to tackle the randomness in vehicle/train load effects, Weibull 
distribution [10], Gamma distribution [11] and Lognormal distribution [12], etc., were often used to give the best fit of the monitored or simulated stress ranges or stress amplitudes.

While the uncertainties in material properties and external loads can be depicted through laboratory tests and inspection/monitoring, the life prediction models remain uncertain and are more complex to develop. In general, existing fatigue prediction models can be classified into two groups: (1) S-N curve-based models [9-11] and (2) the fracture mechanics models. In the former, the Palmgren-Miner rule is often used, and the effectiveness of such methods depends on the classification of concerned details and the fatigue parameters of S-N curves. As to the fatigue fracture models, their early forms adopt the linear elastic or nonlinear fracture approaches, etc. [13-15]; the continuum damage model is also a useful tool to analyze the engineering failure problems [16,17]; unfortunately, damage variables in the continuum damage mechanics lack of explicit physical meaning and are not easily measured through experiments. Furthermore, probabilistic fatigue models [18-20], such as the combined probabilistic physics-of-failure-based method, the probabilistic time-dependent method, etc., have been proposed and applied to take the uncertainties and time-varying features into consideration. However, these methods were mainly developed for engineering problems at macroscale, whereas recent investigations showed that fracture failure may start from the microscopic scale and gradually spread to the macroscopic scale [21]. Therefore, better understanding of the multiscaling fatigue mechanism is crucial for the rational life prediction.

In this paper, a probabilistic fatigue approach is proposed, which is based on a comprehensive and site-specific vehicle load model, finite element (FE) analysis and the fracture based damage model (i.e., multiscaling and mesoscopic fracture mechanics), and the cable life is consumed when the fatigue crack grows to a critical level. In the analyses, the influence of the mean stress level on the fatigue life [10] is also considered. A case study on the stay cables of the Runyang Cable-Stayed Bridge (RCB) in China, is made for demonstration.

\section{Trans-Scale Formulation for Fatigue Crack Growth of Steel Wire and Cable}

\subsection{Macro/Micro Dual Scale Crack Model}

In this study, the cracking process is depicted using the macro/micro dual scale crack model, which is based on the concept of restraining stress zone that reflects the material damage. Assuming that a region with the size of $a$ is cut at the fatigue source point, a macro/micro dual scale crack model can be established as shown in Figure 1 [22], where $r$ is a distance measured from the crack tip, and related to the crack propagation segment size at each time. The front of the zone is a V-shape notch which is simplified from the intergranular and transgranular defects with different grain boundary conditions. The restraining stresses would prevail on the cut surfaces denoted by $\sigma_{0}$. The damage degree can be expressed by the ratio of restraining stress to applied stress $\sigma_{\infty}$. Initially, the stress ratio $\sigma_{0} / \sigma_{\infty}=1$ when the value of crack size $a$ is very small. As the damage development and the crack size $a$ increase with the cycle number of local load, the stress ratio gradually drops from 1 to 0 , indicating the development of a fatigue crack from micro-scale to macro-scale [18]. Hence, the macro/micro dual crack model can describe the total fatigue process from micro to macro scales in a consistent way instead of dividing a continuous fatigue process into two different stages [23].

As wires and cables only bear tension, the tension crack (mode I) is the most common pattern, and, in this study, the stress along the wire (one dimensional) is analyzed for simplicity [22-27], though the stress distribution is much more complex with three-dimensional stresses. Furthermore, at the micro scale, the material is anisotropy, while in the analysis at the macro scale, the isotropic elasticity assumption is often used [24]. The material properties may change as the damage develops from micro to macro scale $[17,28]$. Therefore, different values for the Poisson's ratio and shear modulus are used at micro and macro scale, respectively. In the macro/micro dual scale crack model, the expression of the macro/micro dual scale strain energy density factor for the tension mode crack can be obtained using 
Equation (1) [24], where the superscript "macro" and subscript "micro" indicate that $\Delta S_{\text {micro }}^{\text {macro }}$ is related to both microscopic and macroscopic factors.

$$
\begin{gathered}
\Delta S_{\text {micro }}^{\text {macro }}=a \frac{2\left(1-2 v_{\text {micro }}\right)\left(1-v_{\text {macro }}\right)^{2} \sigma_{\Delta} \sigma_{m}}{G_{\text {macro }}} G^{*}\left(1-\sigma^{*}\right)^{2} \sqrt{\frac{d}{r}}, \\
G^{*}=\frac{G_{\text {micro }}}{G_{\text {macro }}}, \sigma^{*}=\frac{\sigma_{0}}{\sigma_{\infty}}, d=d^{*} \cdot d_{0}, \\
\sigma_{\Delta}=\sigma_{\max }-\sigma_{\min }, \sigma_{m}=\frac{\sigma_{\max }+\sigma_{\min }}{2} .
\end{gathered}
$$

$v_{\text {micro }}$ and $v_{\text {macro }}$ are the microscopic and macroscopic Poisson's ratios, while $G_{\text {micro }}$ and $G_{\text {macro }}$ are the microscopic and macroscopic shear module, respectively. $d^{*}$ is the micro/macro characteristic size ratio, and $d$ is the characteristic size of the local region, which can distinguish the regions of microscopic and macroscopic effects. $d_{0}$ is the grain characteristic size of the material, for steel, it can be taken as $10^{-3} \mathrm{~mm}$ [25]. $\sigma_{\Delta}$ and $\sigma_{m}$ are the stress range and the mean stress caused by cycle loading, respectively, which can be obtained according to $\sigma_{\max }$ and $\sigma_{\min }$ of the stress time-history along the axis of the cable.

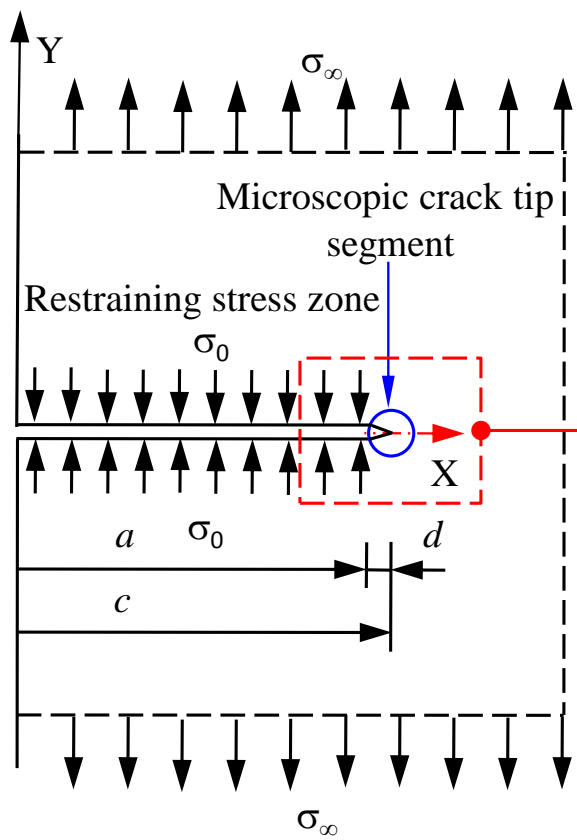

Invisible at the macroscale

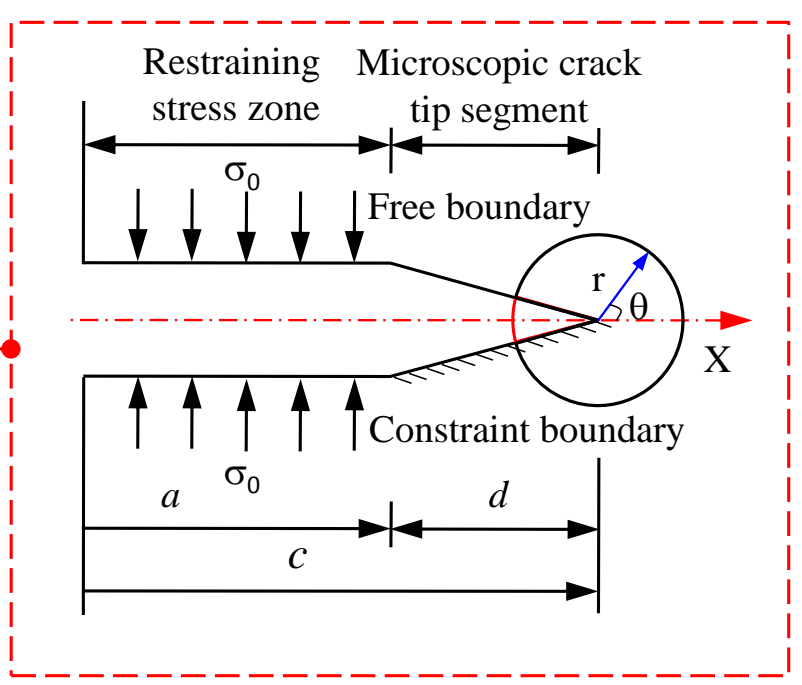

Enlarge view at the microroscale

Figure 1. Macro/micro dual scale crack model. Adapted with permission from [22], Copyright 2006, Elsevier Ltd.

\subsection{Trans-Scale Formulation for Fatigue Crack Growth of Steel Wire}

Previous studies $[23,29,30]$ showed that the fatigue crack in steel wires initially has a circular front and then gradually changes to a straight line crack front and finally fractures without necking effect, exhibiting the brittle characteristics. In spite of the surface effect, a simplified crack model with an equivalent straight front in instead of clam-shell configuration shown in Figure 2 is adopted, according to the assumption that the crack depths in the direction of crack propagation are the same. The equivalent edge crack depth $a_{c}$ will remain the same as the crack size $a$. Hence, according to the 
dual scale fatigue edge crack model, the fatigue crack growth rate $d a / d N$ from micro to macro can be described through the following Equation [24]:

$$
\frac{d a}{d N}=B\left(\Delta S_{\text {micro }}^{\text {macro }}\right)^{m},
$$

where $N$ stands for the number of load cycle. $B$ and $m$ are two material fatigue parameters, which can be obtained from laboratory tests. Figure 3 shows the relation between $d a / d N$ and $\Delta K$ (the amplitude of stress intensity factor) for high strength galvanized steel wires in logarithmic coordinate system, ignoring the mean stress effect, where trans-dimension effect is represented through a straight line [29]. Based on the method in [30], the crack growth rate $d a / d N$ can be substituted into the logarithmic form of Equation (4), and $B$ can be determined according to the slope in Figure 3. For the high strength steel wire, $m$ is approximately equal to $1[30]$.
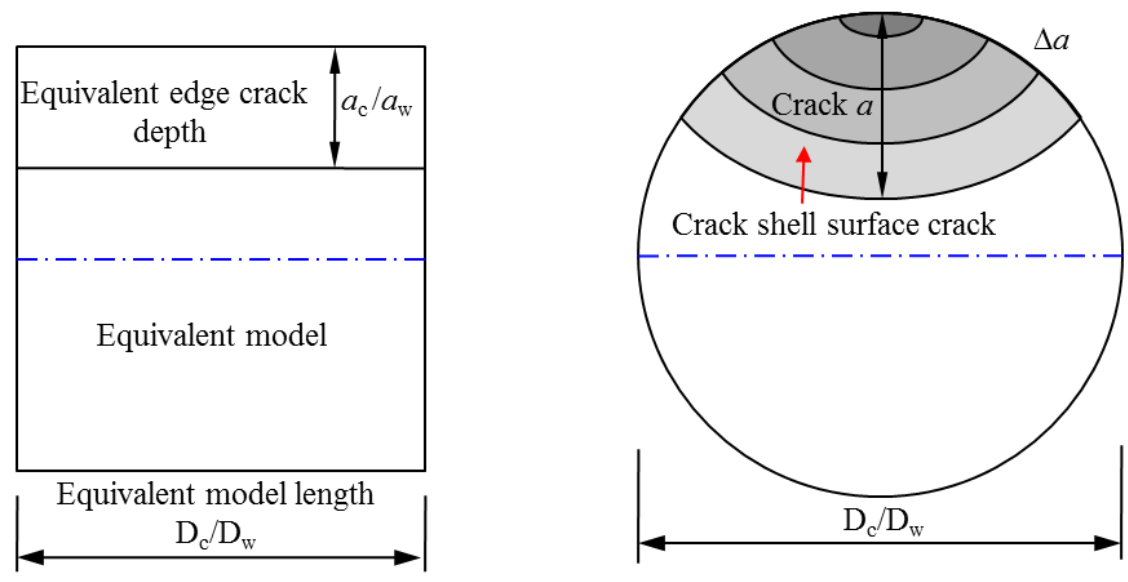

Figure 2. Crack and equivalent depth of steel wire. Adapted with permission from [30], Copyright 2008, Springer.

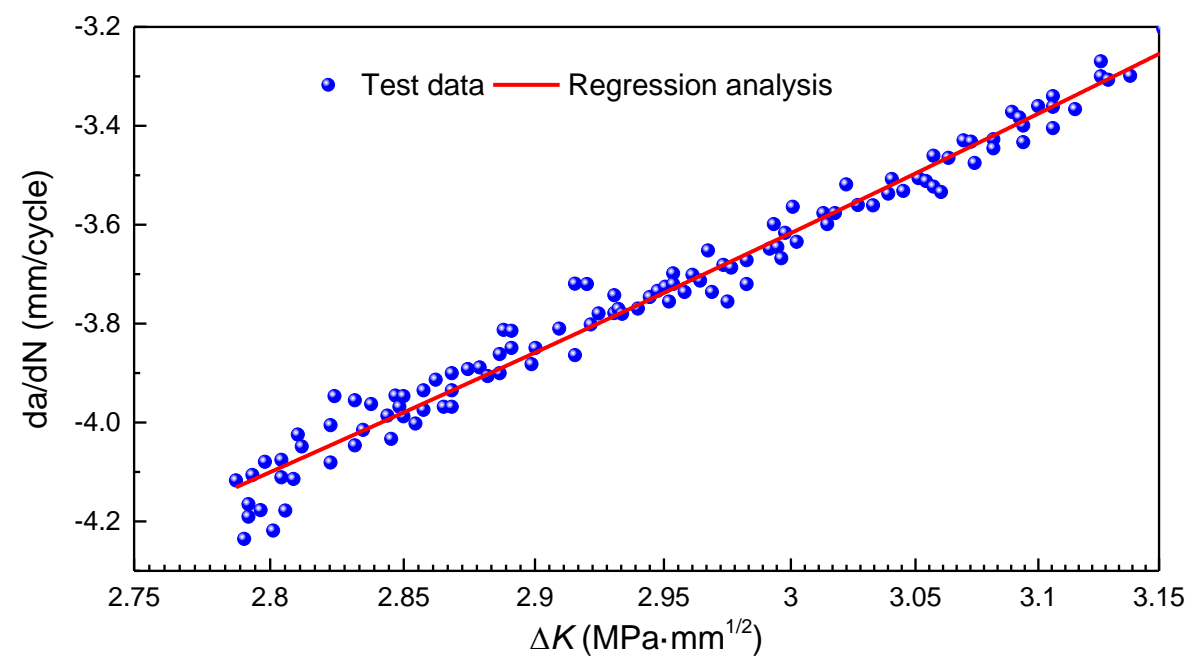

Figure 3. $d a / d N$ versus $\Delta K$ in logarithmic coordinate system. Reproduced with permission from [30], Copyright 2008, Springer.

\subsection{Fatigue Crack Growth of Cable}

A cable is comprised of strands of steel wires wrapping in polymeric tubes with spacing filled by polymers and matrix. Since the cable is no longer homogeneous, the crack growth should be distinguished from that in the steel wire; therefore, extension of the crack growth model in steel wires 
is needed. In this study, the differences in material properties and strengths between cables and wires are considered. The fatigue crack growth with depth $a$ in a cable can be depicted by Equation (4), while the values of $B$ and $m$ are different from those for steel wires. In addition, $\sigma_{\Delta}$ and $\sigma_{m}$ should be obtained using the rain-flow counting [31], based on the stress time-histories of cables due to random vehicle loads.

Assuming that the material and geometric parameters are fixed [32], as shown in Equation (5), the crack profile is simplified with an equivalent straight front shown in Figure 2. The relationship between $a$ and $N$ can be computed for $m=1$ by integrating Equation (4), as shown in Equation (6).

$$
\begin{gathered}
G^{*}=\frac{G_{\text {macro }}}{G_{\text {micro }}}=2, \sigma^{*}=\frac{\sigma_{0}}{\sigma_{\infty}}=0.3, d^{*}=\frac{d_{0}}{d_{\infty}}=1, \frac{d_{0}}{r}=1, v_{\text {micro }}=0.4, \\
\ln [a(N)]=B \frac{0.392\left(1-v_{\text {macro }}\right)^{2} \sigma_{\Delta} \sigma_{m}}{G_{\text {macro }}}\left(N-N_{0}\right) .
\end{gathered}
$$

As a result, a can be expressed as follows [33],

$$
a(N)=a_{0} e^{B \frac{0.392\left(1-v_{\text {macro }}\right)^{2} \sigma_{\Delta} \sigma_{m}}{G_{\text {macro }}}\left(N-N_{0}\right)}
$$

where $a_{0}$ and $N_{0}$ are the depth and cycle number of the initial crack, and the initial value follows the normal distributions, with a mean value and deviation of $0.01 \mathrm{~mm}$ and $0.012 \mathrm{~mm}[29,34]$, respectively, and $N r=N-N_{0} . B$ and $v_{\text {micro }}$ can be taken as $1.06 \times 10^{-6}$ and 0.3 , respectively [35]. According to the elastic mechanics, the following relationship presented in Equation (8) is adopted between shear modulus and elastic modulus:

$$
G_{\text {macro }}=\frac{E_{c}}{2\left(1+v_{\text {macro }}\right)} .
$$

To consider the influence of composite construction on the elastic modulus of the cable, the following Equation (9) is adopted [36]:

$$
E_{c}=\beta E, \beta \leqslant 1.0,
$$

where $E$ is the elastic modulus of steel wire and $\beta$ can be taken as 0.81 [37].

Consequently, Equation (10) can be obtained as follows

$$
a\left(N_{r}\right)=a_{0} e^{B \frac{0.555 \sigma_{\Delta} \sigma_{m}}{E_{\mathcal{C}}} N_{r}}
$$

\section{FE Modeling of the Runyang Cable-Stayed Bridge}

\subsection{Bridge Description}

The Runyang Bridge, open to traffic in 2005, consists of a suspension bridge (with a main span of $1490 \mathrm{~m})$ and a cable-stayed bridge $(175.4 \mathrm{~m}+406 \mathrm{~m}+175.4 \mathrm{~m})$, as shown in Figure 4 . The RCB has a streamlined, closed, flat, steel-box girder supported by 52 cables on each side. The cables consist of unbounded high-strength parallel strands coated by double synchronous extrusion high-density polyethylene (HDPE) protection tubes, as shown in Figure 5. Each cable has a nominal diameter of $80 \mathrm{~mm}$, consisting of 37 steel strands, and the section area of the cable is $5.02 \times 10^{-3} \mathrm{~m}^{2}$. The nominal fracture strength of the steel strand is no less than $1860 \mathrm{MPa}$ consisting of seven steel wires, whose nominal diameter is $5 \mathrm{~mm}$ and the elastic modulus is $1.998 \times 10^{5} \mathrm{MPa}$. 


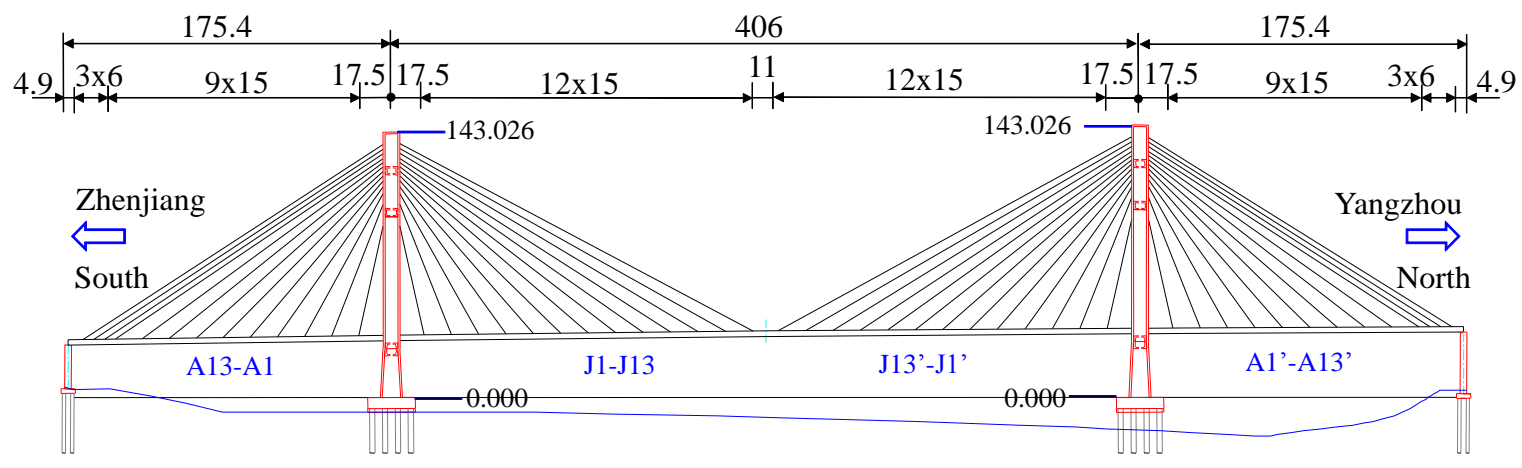

Figure 4. Profile of the Runyang Cable-Stayed Bridge (dimensions in meter).

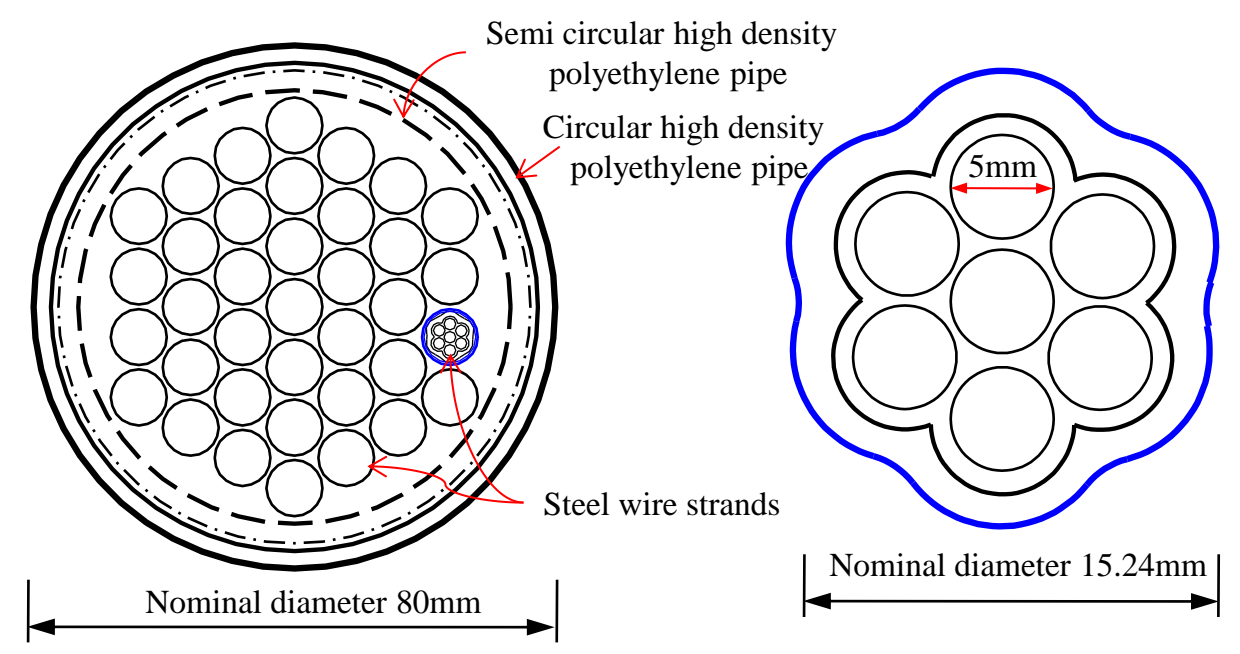

Figure 5. Cross-sections of cable and strands.

\subsection{FE Modeling}

In order to investigate the fatigue behavior of cables of the bridge, a FE model of the RCB is developed using the FE program ANSYS (Version 12.0, ANSYS, Inc.: Drive Canonsburg, PA, USA, 2009) [13], as shown in Figure 6. The towers are modeled using the 3D iso-parametric beam elements (i.e., the Beam4 element in ANSYS) having six degrees of freedom (DOFs) at each node. The stayed-cables are modeled using the 3D linear elastic link elements (i.e., the Link10 element) with three DOFs for each node. Those link elements are defined to bear tension only. The cable stresses in the equilibrium configuration are input in terms of initial strains. The material properties and real constants (i.e., areas of cross-section, moments of inertia, etc.) are strictly calculated and assigned to the corresponding elements. The box girders are modeled using shell elements (i.e., the Shell181 element). To reduce the number of elements, the orthotropic decks and bottom plates of the girder are modeled respectively using a layer of plates without U-ribs, and these plates are assigned with orthotropic material properties. However, the decks near the mid-span are refined, so as to facilitate the application of moving loads at the mid-span. The beam 188 elements are used simulating the braced truss diaphragms. The concrete and steel blocks, placed inside the box-girders at two side spans to adjust the configuration of the bridge, are modeled using the Mass21 element. Each end of the girder is coupled with one tower cross-beams, except that the longitudinal displacement is free. During the analysis, the large-deflection effect option is selected. 


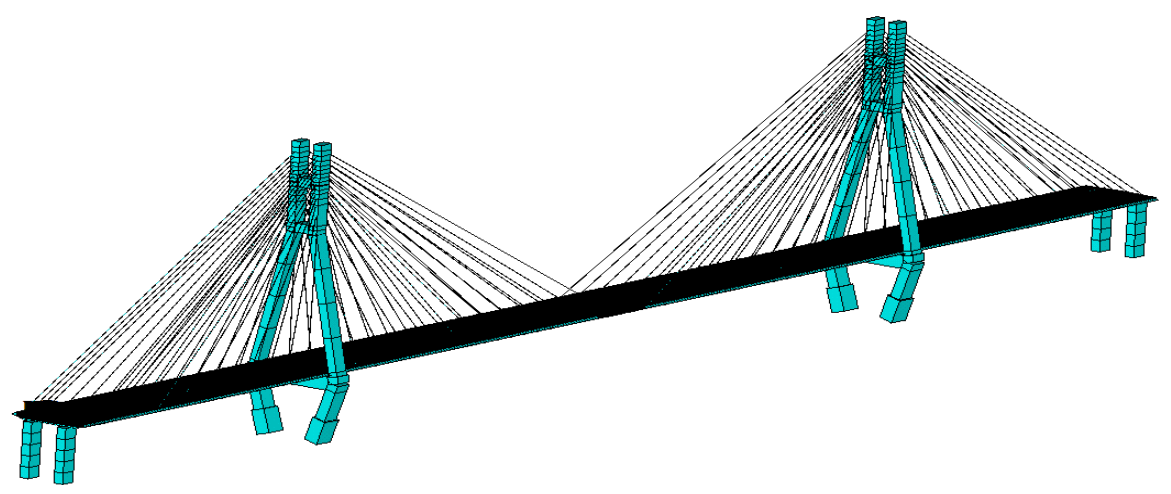

Figure 6. FE model of the Runyang Cable-stayed Bridge.

\subsection{Validation of FE Model}

First, the cable forces under gravity load are calculated and are compared with the test results (half bridge), as shown in Figure 7, where good agreement is observed, showing the effectiveness of the FE model. It is worth noting that the forces of cables near piers, pylons and mid-span are relatively larger. Note that the cables in Figure 4 are labeled from "Zhenjiang" to the south tower as A13, A12, ..., and $\mathrm{A} 1$, from the south tower to mid-span as $\mathrm{J} 1, \mathrm{~J} 2, \ldots$, and $\mathrm{J} 13$, from mid-span to the north tower as $\mathrm{J} 1^{\prime}$, $\mathrm{J} 2$ ' , ..., and $\mathrm{J} 13^{\prime}$, from the north tower to "Yangzhou" as $\mathrm{A} 1^{\prime}, \mathrm{A} 2{ }^{\prime}, \ldots$, and $\mathrm{A} 13^{\prime}$, respectively.

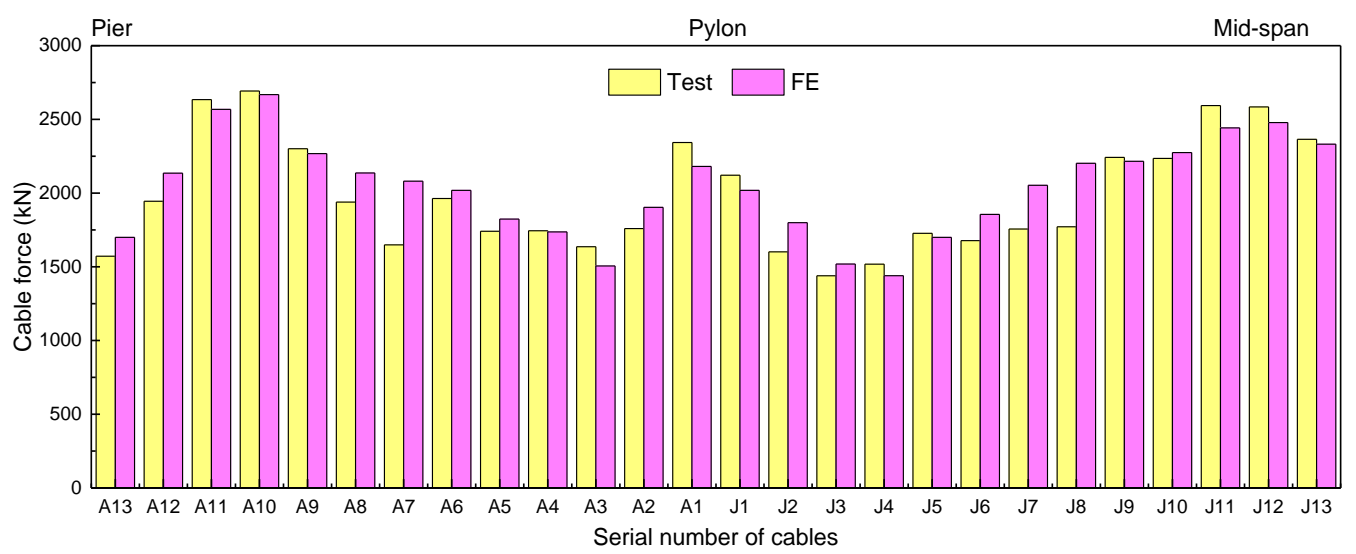

Figure 7. Comparison between calculated and measured cable forces (under gravity load).

In addition, one static load case (i.e., load case 1) in the completion test of the bridge, as shown in Table 1, is randomly selected to further validate the force increments under vehicle loads. As shown in Figure 8, the calculated force increments, especially for the long cables near piers and mid-span are in good agreement with the measured ones.

Table 1. Description of load case 1.

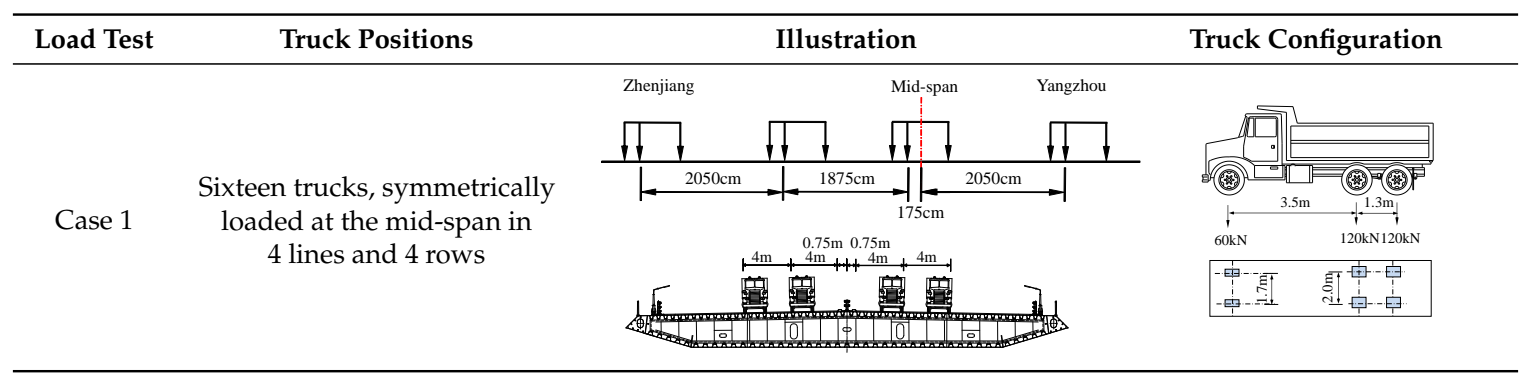




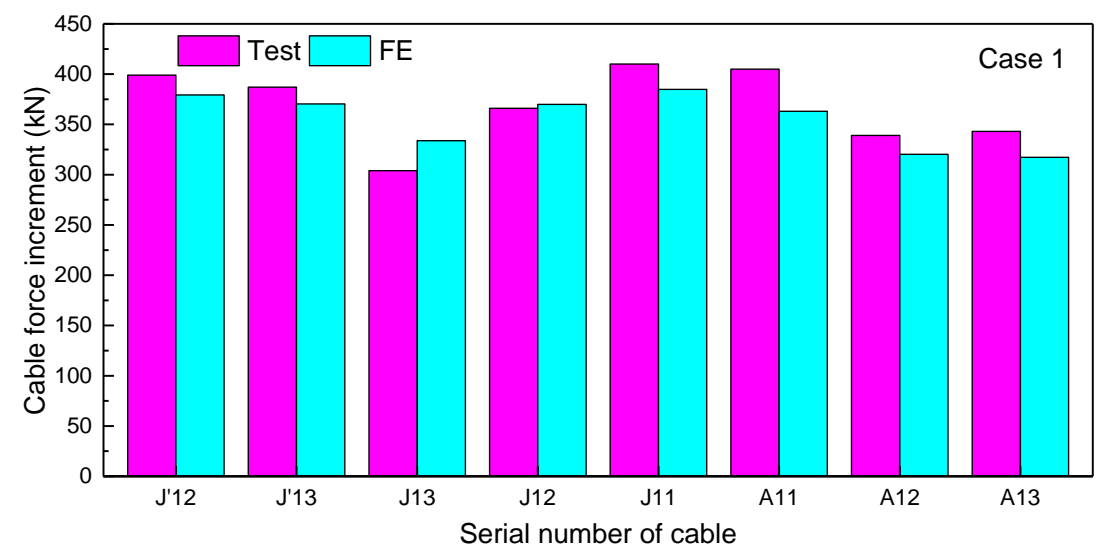

Figure 8. Calculated and measured force increments of cables (load case 1).

\subsection{Force Analysis in Cables}

Figure 9 further shows the force time-histories of the cable J13 (randomly selected), when a truck in case 1 is traveling in different lanes. It is observed that the cable force is influenced by the passing truck within a distance of about $52.5 \mathrm{~m}$, especially within $15 \mathrm{~m}$. Transversally, though in general the force responses are similar, the peak values are larger when the truck is in outer and middle lanes than in the inner lane. Therefore, for accurate evaluation of cable life, transversal and longitudinal positions of the cable should be considered.

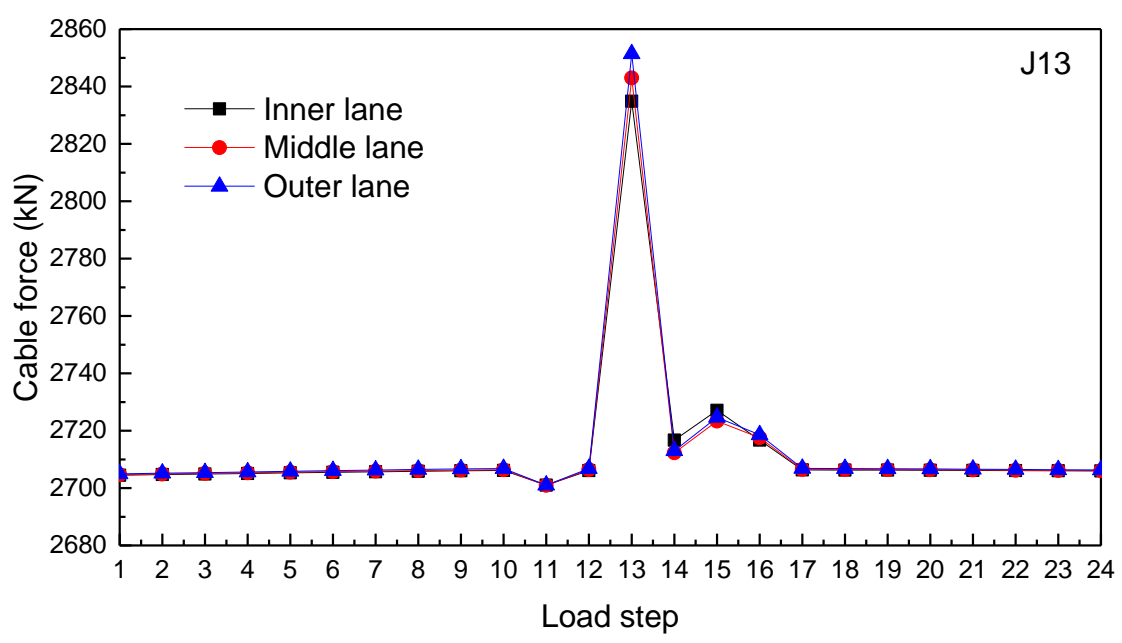

Figure 9. Force time-histories of the cable J13.

\section{Fatigue Life Prediction of Bridge Cables}

\subsection{Vehicle Load Model}

According to the records from toll stations of the RCB [13], there were a total of 371,167 vehicles passing through the bridge during 28 July 2011 to 31 August 2011. Information including the types of vehicles, number of vehicles in each type, number of axles, and axle weights, etc., is obtained and analyzed. Taking the probabilistic properties of axle weights for example, as summarized in Table 2, there are mainly six types of vehicles crossing the bridge, and the axle weights of most types of vehicles are described by a single-peak probability density function (PDF); however, for the last three types, multi-peaks exist in the PDFs, and therefore, a weighted sum of PDFs are used to describe such distributions. 
Using the video camera, the transversal positions (i.e., outer lane, middle lane or inner lane) are also identified, as shown in Table 3. It is observed that 36.65 percent and 42.03 percent vehicles ran in the middle lane and inner lane (i.e., the fast lane), respectively; whereas 21.32 percent vehicles ran in the outer lane (i.e., the slow lane). For the vehicle type 1 for light weight, most of them (i.e., 41.23 percent) were in the fast lane, and only 9.7 percent were in the slow lane. However, for the vehicle type 6 with heavy weight, their lane occupation was just opposite to that of vehicle type 1 . Most heavy trucks were in the middle lane and the slow lane, while only a small portion of them were in the fast lane.

Table 2. Probabilistic properties of axle weights (dimensions in $\mathrm{kN}$ ).

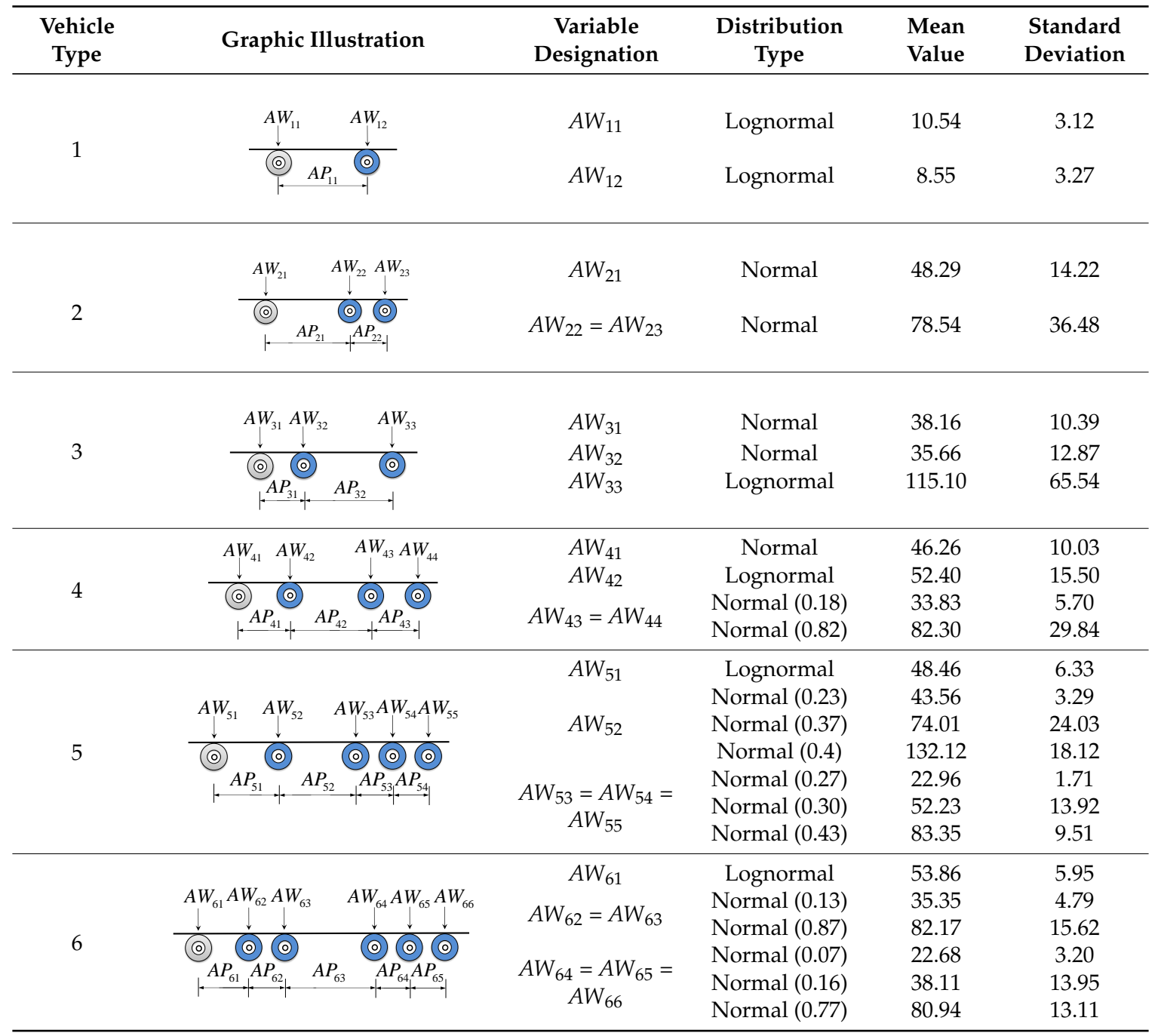

Table 3. Constitution of vehicles.

\begin{tabular}{ccccc}
\hline \multirow{2}{*}{ Vehicle Type } & \multirow{2}{*}{ Percentage in Traffic Volume (\%) } & \multicolumn{2}{c}{ Percentage in Each Lane (\%) } \\
\cline { 3 - 5 } & & Outer Lane & Middle Lane & Inner Lane \\
\hline 1 & 76.66 & 9.70 & 25.74 & 41.23 \\
2 & 0.65 & 0.36 & 0.26 & 0.03 \\
3 & 1.57 & 0.60 & 0.87 & 0.10 \\
4 & 1.64 & 0.92 & 0.67 & 0.04 \\
5 & 2.54 & 1.31 & 1.17 & 0.06 \\
6 & 16.94 & 8.43 & 7.94 & 0.57 \\
\hline
\end{tabular}




\subsection{Fatigue Analysis Approach}

To obtain probabilistic distributions of $\sigma_{m} \sigma_{\Delta}$ and $N c$, an analysis approach is developed in the MATLAB (Version R2009a, MathWorks, Inc.: Apple Hill Drive Natick, MA, USA, 2009) environment and is outlined as follows:

(1) According to the vehicle load model in Tables 2 and 3 a series of vehicles are generated according to the distribution of the vehicle type, the transversal position of vehicle loads, axle loads and the axle spacing by using the truncated Latin Hypercube sampling (LHS) [38] or random sampling.

(2) According to the vehicle parameters determined in the above step, loads of a given vehicle are applied on the FE model in ANSYS. Each load step corresponds to a static FE analysis, and after each load step, the loads move forward to simulate the movement of the vehicle. Thereafter, the stress time-histories of a particular vehicle can be obtained.

(3) Rain-flow counting [31] is conducted to obtain the mean stresses, the stress ranges and the corresponding number of cycles; after that, regression analysis is performed to obtain the PDFs of $\sigma_{m} \sigma_{\Delta}$.

(4) According to Equations (9) and (10), the fatigue life can be calculated as follows:

$$
T=\frac{N_{r}}{365 \times A D V \times N c}=\left[\frac{1.805 E \ln \left(a_{c r} / a_{0}\right)}{B(1+D L A)^{2} \sigma_{m} \sigma_{\Delta}}\right] /(365 \times A D V \times N c),
$$

where $T$ is the fatigue life (in year) and $A D V$ represents the number of average daily vehicles. $D L A$ is the coefficient of dynamic load amplification, which has a mean value of 0.057 and the COV of 0.8 [39]. The critical depth of crack, $a_{c r}$, is calculated according to the critical wire broken rate of a cable, which follows a normal distribution with the mean value of $4 \mathrm{~mm}$ in this study [40]. Considering the high level of uncertainty of material properties, $B$ and $E$ are treated as random variables, with their probabilistic properties listed in Table 4.

Table 4. Random variables used in fatigue reliability analyses.

\begin{tabular}{cccccc}
\hline $\begin{array}{c}\text { Variable } \\
\text { Designation }\end{array}$ & Meaning of Variable & $\begin{array}{c}\text { Distribution } \\
\text { Type }\end{array}$ & Mean Value & COV & Source \\
\hline$B$ & Fracture parameter & Lognormal & $1.06 \times 10^{-6}$ & 0.63 & $\begin{array}{c}\text { Fisher [41] } \\
\text { Elachachi et al. [20] } \\
E\end{array}$ \\
$a_{0}$ & Initial crack depth & Nognormal & $2.0 \times 10^{5} \mathrm{MPa}$ & 0.05 & $\begin{array}{c}\text { Mahmoud [29]; } \\
\text { Molent [34] }\end{array}$ \\
$a_{\mathcal{C}}$ & Critical crack depth & Normal & $4 \mathrm{~mm}$ & 0.2 & MCCHSRI [40] \\
$D L A$ & Dynamic load amplification factor & Normal & 0.057 & 0.8 & AASHTO [39]; \\
& & & & & NCHRP [42] \\
\hline
\end{tabular}

\subsection{Results and Discussion}

According to the above analysis method, the probabilistic distributions of $\sigma_{m}, \sigma_{\Delta}$ and $\sigma_{m} \sigma_{\Delta}$ of cables J13, J12 and J11 are obtained, as shown in Figure 10, where it is observed that these distributions can be represented through normal or lognormal PDFs. Compared with cables J11 and J12, the longer cable J13 may have a slightly smaller mean stress, which is consistent with the calculated and measured results in Figure 7, while it is subjected to larger stress range. Based on the PDFs of $\sigma_{m} \sigma_{\Delta}$ and the probabilistic distributions of $N c$, the probabilistic fatigue lives of the cables J13, J12 and J11 are obtained using Equation (12) from Table 5, and it is observed that the mean lives of cables are 29.11, 34.85 and 44.54 years, respectively. However, the standard deviation of fatigue lives of the three cables are considerable, being 10.32, 13.15 and 17.47 years, respectively, indicating that there are high possibilities for the cables to have a shorter life than designed (i.e., 30 years). It is also observed from Figure 10 that longer cables show shorter lifetime, and one reason is that in the Runyang Cable-Stayed Bridge, longer cables are subjected to larger loads, resulting in larger stress amplitudes, as shown in Figure 10d-f. It is 
also worth noting that in material engineering, a specimen with longer length has a shorter lifetime due to the higher probability of having a weaker link [43].

Table 5. Predicted fatigue lives of cables.

\begin{tabular}{ccccc}
\hline \multirow{2}{*}{ Serial Number of Cables } & \multicolumn{2}{c}{$\sigma_{m} \sigma_{\Delta}\left(\mathbf{M P a}^{\mathbf{2}}\right)$} & \multicolumn{2}{c}{$\boldsymbol{T}$ (year) } \\
& $\mu_{\mathbf{l n}}$ & $\delta_{\text {ln }}$ & $\mu$ & $\sigma$ \\
\hline $\mathrm{J} 13$ & 4858.193 & 0.716 & 29.11 & 10.32 \\
$\mathrm{~J} 12$ & 4059.391 & 0.716 & 34.85 & 13.15 \\
$\mathrm{~J} 11$ & 3175.808 & 0.428 & 44.54 & 17.47 \\
\hline
\end{tabular}

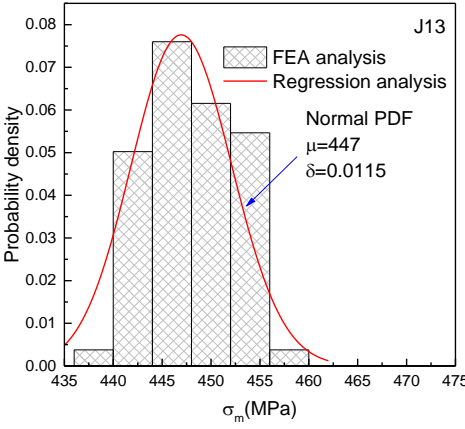

(a)

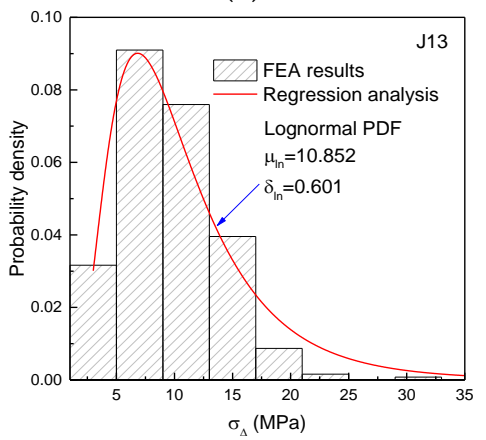

(d)

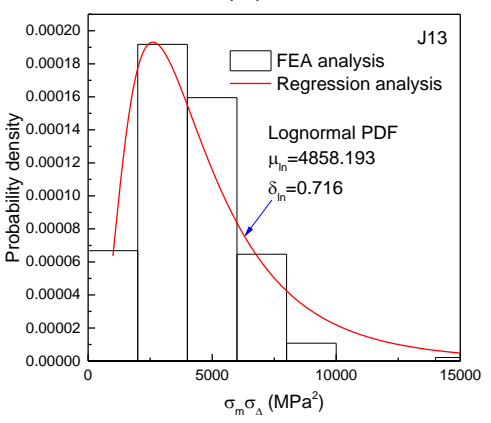

(g)

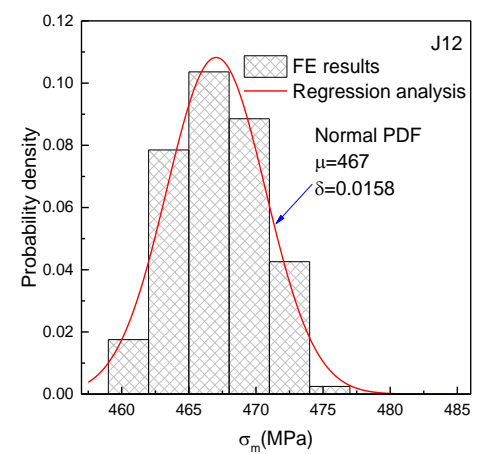

(b)

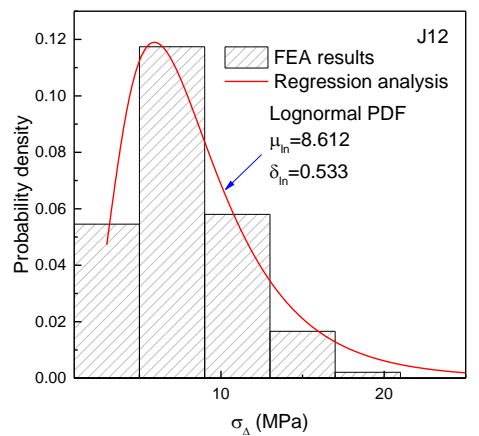

(e)

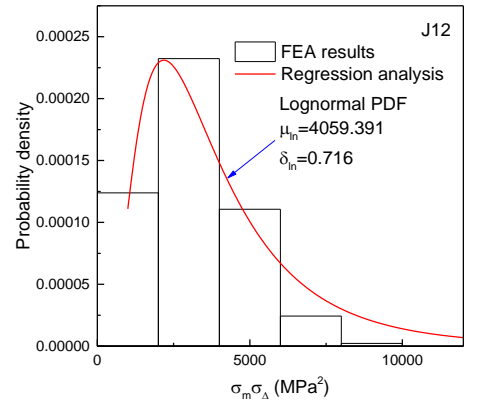

(h)

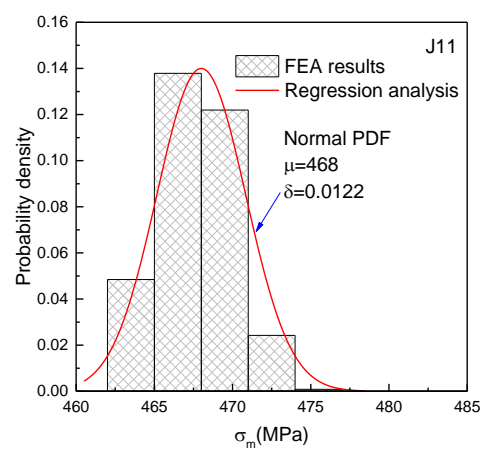

(c)

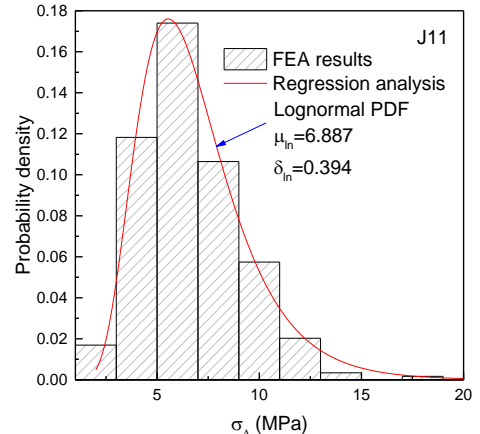

(f)

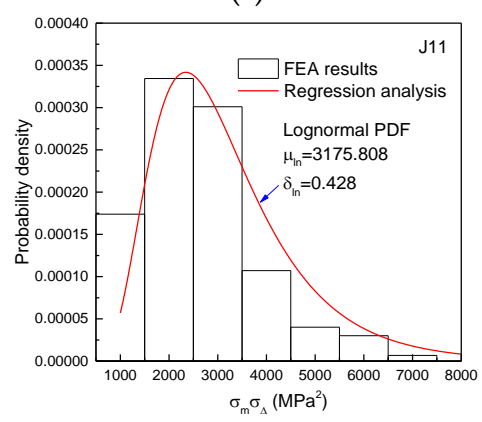

(i)

Figure 10. (a-c) probabilistic density functions of $\sigma_{m} ;(\mathbf{d}-\mathbf{f})$ probabilistic density functions of $\sigma_{\Delta}$; (g-i) probabilistic density functions of $\sigma_{m} \sigma_{\Delta}$.

\section{Conclusions}

This paper presents the probabilistic fatigue life prediction of bridge cables based on multiscaling and mesoscopic fracture mechanics. According to the methodologies and assumptions adopted in this paper, the following conclusions are drawn. 
1. Fatigue crack growth in stay cables is a multiscale process, influenced not only by the initial defects, material properties, and also by some global parameters, such as cable length, mean stress, longitudinal position and vehicle loads, etc. According to the FE analysis, long cables near bridge piers, pylons and mid-span may be more prone to fatigue than the others, and transversal positions of vehicles may influence the cable force, which calls for a more comprehensive vehicle load model including lane occupation.

2. The fatigue crack growth, on the other hand, abounds with uncertainties, so that a probabilistic analysis approach is proposed, which is based on a probabilistic vehicle load model, finite element analysis and multiscaling and mesoscopic fracture mechanics. The proposed uncertain parameters, with their probabilistic properties, are defined and a demonstration study is made.

3. According to the probabilistic FE analyses, the mean lives of the three cables are ranging from 29.11 to 44.54 years; however, the standard deviation of fatigue lives of the three cables are considerable, indicating that there are high possibilities for the cables to have a shorter life than designed.

Acknowledgments: Support from the Natural Science Foundation of Jiangsu under Grant No. BK20130023, Jiangsu Transportation Department under Grant No. 2014Y02 and the Graduate Research Innovation Project of Jiangsu Province under Grant No.KYLX15-0087 is gratefully acknowledged.

Author Contributions: Zhongxiang Liu collected and processed the data, made the calculation, initiated the manuscript draft preparation, reviewed and approved the final draft. Tong Guo conceptualized and designed the study, analyzed the data, revised the manuscript, reviewed and approved the final draft. Shun Chai assisted in background literature search, prepared the tables, reviewed and approved the final draft.

Conflicts of Interest: The authors declare no conflict of interest.

\section{References}

1. Ren, W.X. Ultimate behavior of long-span cable-stayed bridges. J. Bridge Eng. 1999, 4, 30-37. [CrossRef]

2. Xie, X.; Li, X.Z.; Shen, Y.G. Static and dynamic characteristics of a long-span cable-stayed bridge with CFRP cables. Materials 2014, 7, 4854-4877. [CrossRef]

3. Li, S.L.; Xu, Y.; Zhu, S.Y.; Guan, X.C.; Bao, Y.Q. Probabilistic deterioration model of high-strength steel wires and its application to bridge cables. Struct. Infrastruct. Eng. 2015, 11, 1240-1249. [CrossRef]

4. Pipinato, A.; Pellegrino, C.; Fregno, G.; Modena, C. Influence of fatigue on cable arrangement in cable-stayed bridges. Int. J. Steel Struct. 2012, 12, 107-123. [CrossRef]

5. Li, H.; Lan, C.M.; Ju, Y.; Li, D.S. Experimental and numerical study of the fatigue properties of corroded parallel wire cables. J. Bridge Eng. 2011, 17, 211-220. [CrossRef]

6. Stallings, J.M.; Frank, K.H. Stay-cable fatigue behavior. J. Struct. Eng. 1991, 117, 936-950. [CrossRef]

7. Mehrabi, A.B.; Ligozio, C.A.; Ciolko, A.T.; Scott, T.W. Evaluation, rehabilitation planning, and stay-cable replacement design for the hale Boggs Bridge in Luling, Louisiana. J. Bridge Eng. 2010, 15, 364-372. [CrossRef]

8. Nowak, A.S.; Hong, Y.K. Bridge live-load models. J. Struct. Eng. 1991, 117, 2757-2767. [CrossRef]

9. Guo, T.; Frangopol, D.M.; Chen, Y.W. Fatigue reliability assessment of steel bridge details integrating weigh-in-motion data and probabilistic finite element analysis. Comput. Struct. 2012, 112, 245-257. [CrossRef]

10. Basso, P.; Casciati, S.; Faravelli, L. Fatigue reliability assessment of a historic railway bridge designed by Gustave Eiffel. Struct. Infrastruct. Eng. 2015, 11, 27-37. [CrossRef]

11. Kwon, K.; Frangopol, D.M. Bridge fatigue reliability assessment using probability density functions of equivalent stress range based on field monitoring data. Int. J. Fatigue 2010, 32, 1221-1232. [CrossRef]

12. Maljaars, J.; Vrouwenvelder, T. Fatigue failure analysis of stay cables with initial defects: Ewijk bridge case study. Struct. Saf. 2014, 51, 47-56. [CrossRef]

13. Guo, T.; Liu, Z.X.; Zhu, J.S. Fatigue reliability assessment of orthotropic steel bridge decks based on probabilistic multi-scale finite element analysis. Adv. Steel Constr. 2015, 11, 334-346.

14. Gu, M.; Xu, Y.L.; Chen, L.Z.; Xianga, H.F. Fatigue life estimation of steel girder of Yangpu cable-stayed bridge due to buffeting. J. Wind Eng. Ind. Aerodyn. 1999, 80, 383-400. [CrossRef]

15. Llorca, J.; Sánchez-Gálvez, V. Fatigue limit and fatigue life prediction in high strength cold drawn eutectoid steel wires. Fatigue Fract. Eng. Mater. Struct. 1989, 12, 31-45. [CrossRef] 
16. Razmi, J. Fracture mechanics-based and continuum damage modeling approach for prediction of crack initiation and propagation in integral abutment bridges. J. Comput. Civ. Eng. 2015. [CrossRef]

17. Ladani, L.J. Successive softening and cyclic damage in viscoplastic material. J. Electron. Packag. $2010,132$. [CrossRef]

18. Chookah, M.; Nuhi, M.; Modarres, M. A probabilistic physics-of-failure model for prognostic health management of structures subject to pitting and corrosion-fatigue. Reliab. Eng. Syst. Saf. 2011, 96, 1601-1610. [CrossRef]

19. Zhu, S.P.; Huang, H.Z.; Ontiveros, V.; He, L.P.; Modarres, M. Probabilistic low cycle fatigue life prediction using an energy-based damage parameter and accounting for model uncertainty. Int. J. Damage Mech. 2011. [CrossRef]

20. Elachachi, S.M.; Breysse, D.; Yotte, S.; Cremona, C. A probabilistic multi-scale time dependent model for corroded structural suspension cables. Probab. Eng. Mech. 2006, 21, 235-245. [CrossRef]

21. Li, C.X.; Tang, X.S.; Xiang, G.B. Fatigue crack growth of cable steel wires in a suspension bridge: Multiscaling and mesoscopic fracture mechanics. Theor. Appl. Fract. Mech. 2010, 53, 113-126. [CrossRef]

22. Sih, G.C.; Tang, X.S. Asymptotic micro-stress field dependency on mixed boundary conditions dictated by micro-structural asymmetry: Mode I macro-stress loading. Theor. Appl. Fract. Mech. 2006, 46, 1-14. [CrossRef]

23. Toribio, J.; Matos, J.C.; González, B. Micro-and macro-approach to the fatigue crack growth in progressively drawn pearlitic steels at different R-ratios. Int. J. Fatigue 2009, 31, 2014-2021. [CrossRef]

24. Sih, G.C.; Tang, X.S. Micro/macro-crack growth due to creep-fatigue dependency on time-temperature material behavior. Theor. Appl. Fract. Mech. 2008, 50, 9-22. [CrossRef]

25. Tang, X.S.; Wei, T.T. Microscopic inhomogeneity coupled with macroscopic homogeneity: A localized zone of energy density for fatigue crack growth. Int. J. Fatigue 2015, 70, 270-277. [CrossRef]

26. Tang, K.K. Reliability of micro/macro-fatigue crack growth behavior in the wires of cable-stayed bridge. In Proceedings of the 13th International Conference on Fracture, Beijing, China, 16-21 June 2013.

27. Tang, X.S.; Peng, X.L. An energy density zone model for fatigue life prediction accounting for non-equilibrium and non-homogeneity effects. Theor. Appl. Fract. Mech. 2015, 79, 105-112. [CrossRef]

28. Kachanov, M.; Sevostianov, I. On quantitative characterization of microstructures and effective properties. Int. J. Solids Struct. 2005, 42, 309-336. [CrossRef]

29. Mahmoud, K.M. Fracture strength for a high strength steel bridge cable wire with a surface crack. Theor. Appl. Fract. Mech. 2007, 48, 152-160. [CrossRef]

30. Sih, G.C. Multiscale Fatigue Crack Initiation and Propagation of Engineering Materials: Structural Integrity and Microstructural Worthiness: Fatigue Crack Growth Behaviour of Small and Large Bodies; Springer: New York, NY, USA, 2008.

31. Wirsching, P.H.; Shehata, A.M. Fatigue under wide band random stresses using the rain-flow method. J. Eng. Mater. Technol. 1977, 99, 205-211. [CrossRef]

32. Sih, G.C.; Tang, X.S.; Li, Z.X.; Li, A.Q.; Tang, K.K. Fatigue crack growth behavior of cables and steel wires for the cable-stayed portion of Runyang bridge: Disproportionate loosening and/or tightening of cables. Theor. Appl. Fract. Mech. 2008, 49, 1-25. [CrossRef]

33. Polák, J.; Zezulka, P. Short crack growth and fatigue life in austenitic-ferritic duplex stainless steel. Fatigue Fract. Eng. Mater. Struct. 2005, 28, 923-935. [CrossRef]

34. Molent, L.; Barter, S.A. A comparison of crack growth behaviorin several full-scale airframe fatigue tests. Int. J. Fatigue 2007, 29, 1090-1099. [CrossRef]

35. Sih, G.C. Invariant form of micro-/macro-cracking in fatigue. In Structural Integrity and Microstructural Worthiness; Springer: Dordrecht, The Netherlands, 2008; pp. 181-208.

36. Sih, G.C.; Tang, X.S. Fatigue crack growth rate of cable-stayed portion of Runyang bridge: Part I-Cable crack growth due to disproportionate cable tightening/loosening and traffic loading. In Multiscale Fatigue Crack Initiation and Propagation of Engineering Materials: Structural Integrity and Microstructural Worthiness; Springer: Dordrecht, The Netherlands, 2008; pp. 209-247.

37. Fontanari, V.; Benedetti, M.; Monelli, B.D.; Degasperi, F. Fire behavior of steel wire ropes: Experimental investigation and numerical analysis. Eng. Struct. 2015, 84, 340-349. [CrossRef]

38. Stein, M. Large sample properties of simulations using Latin hypercube sampling. Technometrics 1987, 29, 143-151. [CrossRef] 
39. American Association of State Highway and Transportation Officials. Subcommittee on Systems Operations and Management-2008 Strategic Plan; Association of State Highway and Transportation Officials: Washington, DC, USA, 2012.

40. MCCHSRI (Ministry of Communications Chongqing Highway Science Research Institute). Technical Conditions for Hot-Extruding PE Protection High Strength Wire Cable of Cable-Stayed Bridge; GB/T 18365-2001; Ministry of Communications Chongqing Highway Science Research Institute: Beijing, China, 2001.

41. Fisher, J.W. Fatigue and Fracture in Steel Bridges; Wiley: New York, NY, USA, 1984.

42. NCHRP (National Cooperative Highway Research Program). Updating the Calibration Report for AASHTO LRFD Code, 20-07/186; Transportation Research Board, National Research Council: Washington, DC, USA, 2007.

43. Faber, M.H.; Engelund, S.; Rackwitz, R. Aspects of parallel wire cable reliability. Struct. Saf. 2003, 25, 201-225. [CrossRef]

(C) 2016 by the authors; licensee MDPI, Basel, Switzerland. This article is an open access article distributed under the terms and conditions of the Creative Commons by Attribution (CC-BY) license (http://creativecommons.org/licenses/by/4.0/). 